\title{
A prospective study of work related factors and physical exercise as predictors of shoulder pain
}

\author{
H Miranda, E Viikari-Juntura, R Martikainen, E-P Takala, H Riihimäki
}

\begin{abstract}
Objectives-To evaluate the effects of work related and individual factors as well as physical activity and sports on the incidence and persistence of shoulder pain among forestry workers.

Methods-Workers in a large Finnish forestry company replied to a questionnaire (a modified version of the Nordic questionnaire) on musculoskeletal pain and its possible risk factors for 4 consecutive years 1992-5. This 1 year follow up study covers the time 1994-5. Year 1994 was chosen as baseline because in that year the questionnaire contained for the first time more detailed questions about different sports. The response rate in 1995 was $\mathbf{9 0 \%}$. The effects of the predictors on 1 year incidence and persistence of shoulder pain were studied with multivariate logistic regression modelling.

Results-At baseline, 2094 subjects had been free of shoulder pain during the preceding 12 months. After 1 year, 14\% $(n=285)$ reported having mild or severe shoulder pain. Higher age, obesity, and mental stress as well as physically strenuous work and working with trunk forward flexed or with a hand above shoulder level increased the risk of incident shoulder pain. Of the different sports activities, dancing increased the risk of incident pain whereas jogging decreased the risk significantly. Of those 419 workers who had severe shoulder pain at baseline, $55 \%$ $(n=230)$ still had severe pain 1 year later. Higher age, overload at work, and working with a hand above shoulder level increased the risk of persistent severe shoulder pain whereas cross country skiing and general sports activity decreased the risk.
\end{abstract}

Conclusion-Our results support the current view that shoulder pain is the result of many factors, including occupational and individual factors. In this longitudinal study, physical work with a heavy load, awkward work postures, mental stress, and obesity were the risk factors at which preventive measures could be aimed. As a new finding, physical exercise had more protective than impairing effects on the shoulders.

(Occup Environ Med 2001;58:528-534)

Keywords: mental stress; physical work load; sports

Correspondence to:

Dr H Miranda,

helena.miranda@occuphealth.fi

Accepted 17 April 2001
The prevalence of shoulder symptoms seems to be relatively high, varying from $6 \%$ to $25 \%$ in

\section{Main messages}

- The results of our prospective study support the current view that shoulder pain is the result of many factors.

- Physical work with a heavy load, awkward work postures, mental stress, and obesity were the risk factors at which preventive measures could be aimed.

- As a new finding, physical exercise had more protective than impairing effects on the shoulders.

the general population. ${ }^{12}$ During the past decades, the knowledge of aetiological factors, and occupational exposures in particular, has increased and work related factors such as repetitive work, vibration, and awkward postures - for example, severe shoulder flexion or abduction-have been related to shoulder disorders. ${ }^{134}$ Other factors such as age, smoking, and stress have been significant risk factors in some studies. ${ }^{5-7}$

This knowledge is, however, mainly based on studies with cross sectional or case-control design. In a recent systematic review of the available evidence on occupational risk factors for shoulder pain, no longitudinal studies fulfilled the quality criteria. As well as prospective studies, more studies of the effects of leisure time activities were called for. ${ }^{1}$

One of the most popular leisure time activities is physical exercise. ${ }^{8}$ Some sports, such as swimming and playing volleyball, have been related to shoulder problems among athletes. ${ }^{9}{ }^{10}$ There are only a few studies that have investigated both occupational physical loading and participation in leisure time sports as risk factors for shoulder disorders. A cross sectional study of construction workers showed an increased risk for shoulder tendinitis and osteoarthrosis among workers who had been very active in sports. ${ }^{11}$ The risk was even higher if those workers had also reported a high cumulative exposure to load lifting during work. We reported in our earlier cross sectional study an increased risk of shoulder pain among workers who played volleyball. ${ }^{12}$

The objective of this prospective study was to examine the effects of work related and individual factors as well as physical activity and sports on the incidence and persistence of shoulder pain among forestry workers.

\section{Methods}

STUDY POPULATION

In 1992, 7000 employees of a large forestry company in Finland received a questionnaire 




*Variables with significance (at $5 \%$ level) in exploratory analyses. on musculoskeletal pain and potential risk factors. $^{13}$ After two reminders, 5250 (75\%) responded to the questionnaire. A few subjects with rheumatoid arthritis and with part time work were excluded, leaving 5180 subjects in the study population. Follow up questionnaires were sent in 1993,1994 , and 1995 to those who had responded to the previous questionnaire and the response rates were $83 \%, 77 \%$, and $90 \%$, respectively. The corresponding numbers of subjects were 4283, 3312, and 2984. This 1 year follow up study covers the time from 1994 to 1995 . The year 1994 was chosen as baseline because in that year the questionnaire contained for the first time more detailed questions about different sports.

Of those 3312 employees who completed and returned the questionnaire in 1994, 28\% were white collar workers (foremen, management, office clerks, and technical designers) and $72 \%$ were blue collar workers (paper machine process and forest workers). The mean age of the white collar workers was 45.3 (SD 9.2) years and 53\% of those were men. For the blue collar workers, the mean age was 45.3 (SD 9.1) years and $82 \%$ were men.

The baseline study population (3312 employees) represents only $47 \%$ of the original cohort $(n=7000)$ to whom the first questionnaire in 1992 was sent. However, the nonrespondents did not differ remarkably from those who replied several times to the questionnaires. The occurrence of shoulder pain in the previous year was similar among the respondents and non-respondents. The younger subjects replied slightly less often than the older subjects and the men less often than the women, but the differences were small. In $1994,12 \%$ of the respondents were no longer employed by the company. Most of these respondents were older workers and had retired. Ending employment seemed to have no effect on shoulder pain.

QUESTIONNAIRE

The questionnaire (a modified version of the Nordic questionnaire) ${ }^{14}$ contained the following question about shoulder pain: "Estimate the total number of days you have had pain during the preceding 12 months?". A manikin was used to denote the anatomical area. Questions were also asked about symptoms in other body regions. The questionnaire in 1994 contained 11 questions about physical load factors, nine questions about work characteristics, and 24 questions about individual factors. ${ }^{13}$ Questions were asked about physical exercise in general (times a week on the average during the preceding 12 months, at least 20 minutes per session, for example bicycling, swimming, etc). Also, the questionnaire contained a table of 15 different types of sports. The respondents answered how many times a month and how many months during the preceding 12 they had practiced these activities. This table was based on the 1992 questionnaire where an open question of the main sports was included. Those sports, which were assumed to impose the same type of loading on the musculoskeletal system, formed a group (for example, tennis, squash, and badminton formed the group of racquet sports)..$^{12}$

\section{OUTCOMES}

The outcome variables were incident shoulder pain and persistent severe shoulder pain. The questions about shoulder pain at baseline and 
Table 2 Shoulder pain in 1994 and 1995 among forestry workers *

\begin{tabular}{|c|c|c|c|c|c|c|c|c|c|}
\hline & \multicolumn{8}{|l|}{1995} & \multirow[b]{3}{*}{$\%$} \\
\hline & \multicolumn{2}{|c|}{ Healthy } & \multicolumn{2}{|l|}{ Mild } & \multicolumn{2}{|c|}{ Severe } & \multicolumn{2}{|l|}{ All } & \\
\hline & $n$ & $\%$ & $n$ & $\%$ & $n$ & $\%$ & $n$ & $\%$ & \\
\hline \multicolumn{10}{|l|}{ 1994: } \\
\hline Healthy & 1809 & 86 & 161 & 8 & 124 & 6 & 2094 & 100 & $(74)$ \\
\hline Mild & 160 & 50 & 84 & 26 & 77 & 24 & 321 & 100 & (11) \\
\hline Severe & 107 & 25 & 82 & 20 & 230 & 55 & 419 & 100 & (15) \\
\hline All & 2076 & (73) & 327 & (12) & 431 & (15) & 2834 & & (100) \\
\hline
\end{tabular}

$\star 150$ Subjects of the total of 2984 had missing values in the questions on shoulder pain in either year 1994 or 1995 .
The agreement between the general question of weekly physical exercise and the added score based on the different types of sports was investigated with cross tabulations. The respondents seemed to exercise more according to the added score than to the general question. For instance, according to the general question, there were 944 subjects who reported exercising at the most once a week. However, only $42 \%$ of these subjects had an added score lower than 53 and in fact, $23 \%$ had an added score higher than 156.

in the follow up questionnaires had five categories ( 0 days, $1-7$ days, $8-30$ days, $>30$ days but not daily, daily). These categories represent the total number of days with shoulder pain during the 12 months preceding the questionnaire. In the analysis, we combined the first two categories, as we thought that some days with shoulder pain do not necessarily indicate a shoulder disorder. Also, the last two were combined due to the few subjects with daily pain. Hence, we ended up with a three category variable: $0-7$ days (healthy), 8-30 days (mild pain), and $>30$ days (severe pain) during the preceding 12 months. We found in exploratory analyses that the effects of different risk factors on the incidence of shoulder pain seemed to be similar for mild and severe pain. Therefore, we combined the two categories of pain. The dichotomous outcome variable was incident pain versus healthy - that is, those who were healthy in 1994 but reported either mild or severe shoulder pain in 1995 were compared with those who were healthy in both 1994 and 1995.

The dichotomous outcome variable for persistent pain was persistent severe shoulder pain versus no severe shoulder pain-that is, those who reported severe shoulder pain in 1994 and 1995 were compared with those who had severe pain in 1994 but reported no severe pain in 1995.

\section{PREDICTORS}

The possible predictors listed in table 1 were based on the baseline questionnaire in 1994 . For some work load factors, the original question in the questionnaire contained several categories, but as the effect of the variable on shoulder pain was similar in some categories, these categories were combined. Also, some categories with small counts were combined. Continuous variables (such as age and body mass index) were categorised.

We formed indices for the 15 different types of sports; an index represented the number of times a sport was practised each year. The indices were classified into three categories (not at all or only little, moderately, or actively). ${ }^{12}$ Also, we summed all the individual sports indices together to obtain an overall sports activity sum score which represented an overall frequency during the 12 months. This added score was classified into three categories: $0-52,53-156,>156$. The value of 52 equals exercise practised once every week of the year and the value of 156 three times a week on average.
DATA ANALYSIS

Those possible predictors which in our exploratory analyses (cross tabulations) were related to shoulder pain with significance at the $5 \%$ level (marked with an asterisk in table 1), were chosen for the preliminary analyses. In the preliminary analyses of the incidence of shoulder pain, each of these variables was placed one by one in the logistic regression models. The models also included age and sex. All the significant variables in the preliminary models were chosen for the final modelling. We included the following variables in the multivariate model (disregarding the significance): age, sex, and those variables which we were particularly interested in-such as working with a hand above shoulder level, physically strenuous work, mental stress, and sport related factors. Also, the rest of the significant variables in the preliminary models - such as body mass index and other work positionswere put in the multivariate model and the least significant of these variables was eliminated from the model one by one until the final interest which were forced into the model, and those other variables which were significant. No statistical interactions between different predictors were detected.

For persistent severe shoulder pain, the same modelling strategy was used. However, most of the variables of interest in the incidence analyses were not related to persistent pain in the preliminary models. Only working with a hand above shoulder level, cross country skiing, and sports activity added score were associated with persistent pain. Hence, these variables and the other variables, which were significantly models, were put in the multivariate model. We detected no significant interactions between different predictors. All statistical analyses were performed with the GENMOD procedure in the SAS program 6.12 software package.

As well as these main analyses, we restricted the study population to those who had been healthy for at least 3 consecutive years (since 1992) and we investigated the effects of the predictors on incident shoulder pain in this subgroup.

\section{Results}

INCIDENCE OF SHOULDER PAIN

The 1 year incidence of shoulder pain was $14 \%$ (table 2). The results of the preliminary and final multivariate logistic regression models are shown in table 3 . The risk of incident shoulder model included age, sex, those variables of related to pain in the age and sex adjusted 
Table 3 Factors predicting the incidence of shoulder pain: logistic regression models

\begin{tabular}{|c|c|c|c|c|c|}
\hline \multirow[b]{2}{*}{ Predictor } & \multicolumn{2}{|c|}{$\begin{array}{l}\text { Adjusted for age and } \\
\text { sex }\end{array}$} & \multicolumn{2}{|c|}{ Multivariable model } & \multirow[b]{2}{*}{$p$ Value } \\
\hline & OR & $95 \% C I$ & $O R$ & $95 \% C I$ & \\
\hline \multicolumn{6}{|l|}{ Individual factors: } \\
\hline Age $(y)$ & & & & & 0.004 \\
\hline$<35$ & & & 1.0 & & \\
\hline $35-44$ & & & 1.2 & 0.8 to 2.0 & \\
\hline $45-54$ & & & 1.8 & 1.1 to 2.8 & \\
\hline$\geqslant 55$ & & & 2.6 & 1.4 to 4.7 & \\
\hline Sex & & & & & 0.18 \\
\hline Male & & & 1.0 & & \\
\hline Female & & & 1.3 & 0.9 to 1.8 & \\
\hline Body mass index $\left(\mathrm{kg} / \mathrm{m}^{2}\right)$ & & & & & 0.001 \\
\hline$<23$ & 1.0 & & 1.0 & & \\
\hline $23.0-25.9$ & 1.1 & 0.8 to 1.7 & 1.1 & 0.7 to 1.7 & \\
\hline $26.0-28.9$ & 1.8 & 1.2 to 2.6 & 1.7 & 1.1 to 2.6 & \\
\hline$\geqslant 29.0$ & 2.1 & 1.4 to 3.3 & 2.2 & 1.4 to 3.6 & \\
\hline Mental stress & & & & & 0.11 \\
\hline Not at all & 1.0 & & 1.0 & & \\
\hline Only little & 1.4 & 0.9 to 2.0 & 1.3 & 0.8 to 2.0 & \\
\hline To some extent & 1.7 & 1.1 to 2.5 & 1.5 & 1.0 to 2.4 & \\
\hline Rather much or much & 2.1 & 1.3 to 3.5 & 1.9 & 1.1 to 3.3 & \\
\hline Jogging & & & & & 0.012 \\
\hline Not at all or only little & 1.0 & & 1.0 & & \\
\hline Moderately & 0.8 & 0.5 to 1.4 & 0.7 & 0.4 to 1.2 & \\
\hline Actively & 0.4 & 0.2 to 0.9 & 0.3 & 0.1 to 0.8 & \\
\hline Dancing & & & & & 0.087 \\
\hline Not at all or only little & 1.0 & & 1.0 & & \\
\hline Moderately & 1.7 & 1.1 to 2.5 & 1.6 & 1.0 to 2.5 & \\
\hline Actively & 1.3 & 0.8 to 2.1 & 1.4 & 0.8 to 2.5 & \\
\hline \multicolumn{6}{|l|}{ Work related factors: } \\
\hline Physical strenuousness of work & & & & & 0.004 \\
\hline Not at all or rather light & 1.0 & & 1.0 & & \\
\hline Somewhat strenuous & 1.7 & 1.2 to 2.3 & 1.6 & 1.1 to 2.3 & \\
\hline Rather or very strenuous & 2.4 & 1.7 to 3.4 & 2.0 & 1.3 to 3.1 & \\
\hline Working with a hand above shoulder level (h/day) & & & & & 0.57 \\
\hline$<1 / 2$ & 1.0 & & 1.0 & & \\
\hline $1 / 2-1$ & 1.4 & 1.0 to 2.0 & 1.1 & 0.8 to 1.6 & \\
\hline$>1$ & 1.8 & 1.3 to 2.6 & 1.3 & 0.8 to 1.9 & \\
\hline Working with the trunk flexed forward (h/day) & & & & & 0.044 \\
\hline$<1 / 2$ & 1.0 & & 1.0 & & \\
\hline $1 / 2-1$ & 2.1 & 1.5 to 3.0 & 1.7 & 1.2 to 2.5 & \\
\hline $1-2$ & 1.5 & 1.0 to 2.4 & 1.2 & 0.7 to 2.0 & \\
\hline$>2$ & 2.3 & 1.6 to 3.2 & 1.6 & 0.9 to 2.6 & \\
\hline \multicolumn{6}{|l|}{ Twisting movements of the trunk during a workday } \\
\hline Not at all & 1.0 & & & & \\
\hline Little or moderately & 2.9 & 1.3 to 6.7 & & & \\
\hline Much & 5.1 & 2.1 to 12.3 & & & \\
\hline \multicolumn{6}{|l|}{ Working in sitting position (h/day) } \\
\hline$<2$ & 1.0 & & & & \\
\hline $2-4$ & 0.7 & 0.5 to 1.0 & & & \\
\hline$>4$ & 0.7 & 0.5 to 0.9 & & & \\
\hline \multicolumn{6}{|l|}{ Working with rotated neck (h/day) } \\
\hline$<1 / 2$ & 1.0 & & & & \\
\hline $1 / 2-1$ & 1.3 & 1.0 to 1.9 & & & \\
\hline$>1$ & 1.6 & 1.2 to 2.2 & & & \\
\hline
\end{tabular}

pain increased with age; the risk in the oldest group was nearly threefold higher than in the youngest. Likewise, the risk of incident shoulder pain was positively correlated to the body mass index. Also, mental stress and physically strenuous work increased the risk of incident shoulder pain. Working with a hand above shoulder level, twisting movements of the trunk, working with rotated neck, with the trunk flexed forward, or in a sitting position predicted the risk of incident pain in the preliminary models. Of these work postures only working with the trunk flexed forward remained being a risk factor in the final multivariate model. Of the different types of sports, dancing slightly increased the risk of incident shoulder pain whereas jogging decreased the risk, which is to say that those who practised jogging actively had a significantly lower risk of shoulder pain than those who did not practise jogging (OR 0.3, 95\% CI 0.1 to 0.8 ). Other types of sports or the frequency of physical exercise were not associated with the incidence of shoulder pain.
In the subgroup of those respondents who had no shoulder pain in 1992 and in 1993, the effects of the predictors remained similar, except the effect of age, which decreased and the effect of working with a hand above shoulder level, which slightly increased with time.

PERSISTENCE OF SEVERE SHOULDER PAIN

The 1 year persistence of severe shoulder pain was 55\% (table 2). Overload at work predicted the persistent severe pain in our logistic regression models (table 4); the more overload the respondents reported, the higher was the risk. Also, working with a hand above shoulder level increased the risk, but the association was rather weak. Cross country skiing and physical exercise more than 52 times a year decreased the risk of persistent severe pain.

\section{Discussion}

The risk factors that explained the incidence of shoulder pain in this longitudinal study did not differ significantly from the risk factors for the prevalence of shoulder pain in our cross 
Table 4 Factors predicting the persistence of severe shoulder pain: logistic regression models

\begin{tabular}{|c|c|c|c|c|c|}
\hline \multirow[b]{2}{*}{ Predictor } & \multicolumn{2}{|c|}{ Adjusted for sex and age } & \multicolumn{2}{|c|}{ Multivariable model } & \multirow[b]{2}{*}{$p$ Value } \\
\hline & $O R$ & $95 \% C I$ & $O R$ & $95 \% C I$ & \\
\hline \multicolumn{6}{|l|}{ Individual factors: } \\
\hline Age (y) & & & & & 0.0001 \\
\hline$<35$ & & & 1.0 & & \\
\hline $35-44$ & & & 0.9 & 0.3 to 2.6 & \\
\hline $45-54$ & & & 3.6 & 1.3 to 10.2 & \\
\hline$\geqslant 55$ & & & 1.6 & 0.5 to 4.8 & \\
\hline Sex & & & & & 0.15 \\
\hline Male & & & 1.0 & & \\
\hline Female & & & 0.7 & 0.4 to 1.2 & \\
\hline Sports activity added score & & & & & 0.14 \\
\hline $0-52$ & 1.0 & & 1.0 & & \\
\hline $53-156$ & 0.4 & 0.2 to 0.8 & 0.5 & 0.2 to 1.0 & \\
\hline$>156$ & 0.6 & 0.4 to 1.0 & 0.7 & 0.4 to 1.3 & \\
\hline Cross country skiing & & & & & 0.12 \\
\hline Not at all or only little & 1.0 & & 1.0 & & \\
\hline Moderately & 0.4 & 0.2 to 0.7 & 0.5 & 0.3 to 1.1 & \\
\hline Actively & 0.5 & 0.3 to 1.1 & 0.6 & 0.2 to 1.3 & \\
\hline \multicolumn{6}{|l|}{ Work related factors: } \\
\hline Overload at work & & & & & 0.001 \\
\hline Not at all & 1.0 & & 1.0 & & \\
\hline Little & 1.9 & 1.0 to 3.5 & 2.1 & 1.1 to 4.0 & \\
\hline Definite & 3.4 & 1.7 to 6.9 & 3.8 & 1.8 to 8.0 & \\
\hline Working with a hand above shoulder level (h/day) & & & & & 0.42 \\
\hline$<1 / 2$ & 1.0 & & 1.0 & & \\
\hline $1 / 2-1$ & 1.4 & 0.8 to 2.4 & 1.4 & 0.8 to 2.4 & \\
\hline$>1$ & 1.5 & 0.8 to 2.5 & 1.4 & 0.8 to 2.5 & \\
\hline
\end{tabular}

sectional study. ${ }^{12}$ At baseline, shoulder pain was associated with age, previous shoulder injuries, twisting movements of the trunk, working with a hand above shoulder level, mental stress, and playing volleyball. ${ }^{12}$ In this longitudinal study, the individual risk factors for the incidence of shoulder pain were age and body mass index. Age has also been a strong predictor for shoulder pain in some previous studies, ${ }^{5}{ }^{15}$ possibly due to increasing degeneration of the tendons and development of osteoarthrosis in the joints.

In some studies, obesity has been a risk factor for the development of osteoarthrosis in several joints, especially in the knees but also in the hands. ${ }^{16}{ }^{17}$ Biomechanic and metabolic factors have been suggested to explain this relation. In our study, body mass index seemed to be an important risk factor for incident shoulder pain.

Of the work related factors, the subjective estimate of physically strenuous work was a risk factor for the incidence of shoulder pain. Physically strenuous work presumably contains activities (for instance lifting, carrying, pushing, or pulling) which load the shoulder and may cause pain. The effect of the most shoulder load specific variable, working with a hand above shoulder level, decreased in the final multivariate model. Working with the trunk flexed forward seemed to be a stronger predictor for incident shoulder pain. This variable does not directly indicate high shoulder loads. However, working with a hand above shoulder level correlated strongly with working with the trunk flexed forward (data not shown). This means that workers with forward flexed trunk postures often had raised arm postures, but the trunk postures being a stronger predictor in the multivariate model might explain the effects of the raised arm postures.

Overload at work (a sum score variable of difficulty and hurry at work) predicted the persistence of severe pain. Hurry at work may indicate too fast a work pace or poor job control whereas difficulty at work may be a sign of psychologically too demanding work. Poor job control and psychologically demanding work have been related to shoulder pain in some previous studies. ${ }^{1}$

Mental stress was associated with shoulder pain at baseline. ${ }^{12}$ In this follow up study mental stress predicted the incidence of shoulder pain but not the persistence of severe pain. Mental stress has been related to different musculoskeletal problems in some studies. ${ }^{5718}$ In a recent prospective study of neck and shoulder disorders, stress was related to neck and shoulder disorder at baseline but was not associated with the development of the disorder. ${ }^{19}$ Presumably a painful condition causes stress, but whether mental stress is a causal factor for musculoskeletal pain is still under discussion. Our results suggest that mental stress may be an independent predictor for incident shoulder pain.

The frequency of physical exercise (according to the general question or the sports activity added score) was not associated with the incidence of shoulder pain. Of the different types of sports, dancing seemed to increase the risk of incident pain. Dancing often contains movements of the upper limbs, which may cause dynamic or static loads on the shoulder. Furthermore, active jogging decreased the risk of incident shoulder pain significantly. Jogging has often been connected to an increased risk of musculoskeletal symptoms in the lower limbs, ${ }^{20}$ but the preventive effects of jogging on shoulder joints have not been reported before. Also, cross country skiing (especially at a moderate level) decreased the risk of persistent severe shoulder pain. We think that the same type of movement of the shoulder joint could at least partly explain the benefits from these activities. In both sports, the upper arm swings below the horizontal level back and forth repeatedly with none or some external loading 
(pushing with skiing poles). This pendulum movement increases blood circulation in shoulder tendons but does not expose the tendons or the joints to static tension, abduction, or too heavy external loads. Moreover, these sports activities do not involve a high risk of accidental injuries.

At baseline, the risk of pain among active volleyball players was remarkably higher than among those who did not play the game. ${ }^{12}$ Volleyball playing did not, however, predict the incidence of shoulder pain. Many active players had reported shoulder pain in 1994, so they were excluded from the incidence study. The follow up time of this study may have been too short to detect new cases of incident shoulder pain among healthy volleyball players. It is possible that some of the players who have had shoulder problems have stopped playing and those who have continued to play have adapted to the loading of volleyball playing. This would explain why volleyball playing did not predict the 1 year incidence although it presumably increases the risk of shoulder problems. This may also hold true for the other sports that actively stress the shoulder-such as swimming and racket sports-but which only had a neutral effect on incident pain in our study. Also, there seems to be a group of active volleyball players who continue playing despite pain; this would explain the strong association found in the cross sectional study. Unfortunately, the size of this group was too small to show any significant effect in the analyses of persistent severe pain.

Earlier studies have shown that a considerable proportion of people forget their lifetime symptoms. ${ }^{21}$ To diminish this recall error, we used a 12 month questionnaire in this study. For the incidence analyses, the study cohort was defined as those who reported no shoulder pain during the 12 months preceding the baseline questionnaire. However, our data from 1992 and 1993 showed that $26 \%$ of those who did not have shoulder pain in 1994 had had shoulder pain earlier. Some of the incident cases may have experienced recurrent shoulder pain (recurrence from 1992 or 1993 or earlier years) and the risk factors for recurrent pain may differ from the risk factors for incident pain. Therefore, as well as the main analyses, we restricted the study population to those who had been healthy for at least 3 consecutive years (since 1992) and investigated the effects of the predictors in this subgroup. The effects remained largely similar, yet the 95\% confidence intervals (95\% CIs) widened as the size of the study population diminished. This analysis gives support to the fact that our predictors may be true risk factors for the first occurrence of shoulder pain.

The validity of most of the questions about work load has been reported elsewhere. ${ }^{22}$ The correlations between self assessed and observed estimations were relatively high especially among those workers who were free of musculoskeletal pain. The validity of measuring physical activity with a self administered questionnaire is another complex issue and has been discussed in our previous paper. ${ }^{12}$ It is possible that the amount of physical activity is overestimated as the benefits of exercising are appreciated and many people hope to do it regularly. Usually, the heavier or more structured the physical exertion is, the easier and more accurate it is recalled. ${ }^{23}$ In general, self administered questionnaires are reasonably valid and useful tools in assessing physical activity. $^{2425}$

Information bias caused by better recall or overestimation of past exposure among those with current symptoms ${ }^{22}$ was avoided with the prospective study design among painfree subjects in the incidence study. When interpreting the results of this or other similar studies, where the subjects at baseline are symptom free and where the exposure precedes the outcome, there is a tendency to assume a cause-effect relation. But other explanations may exist too. For instance, some factors such as obesity may be indicators of other factors - such as lack of physical fitness. Some people may also be more prone to perceive and report such exposures as physical workloads as well as their symptoms. This may lead to spurious associations. Hence, assumptions of a direct causality between the detected risk factors and the outcome should be made with caution.

One shortcoming of the questionnaire was in the interpretation of the results of persistent pain. The questionnaire did not detect if persistent pain appeared in the same shoulder. However, we assume that the respondents, who reported severe shoulder pain 2 years in a row, had pain on the same side.

In conclusion, the results support the current view that shoulder pain is the result of several factors, including occupational and individual factors. In this longitudinal study, heavy physical work, awkward work postures, mental stress, and obesity were the risk factors, at which preventive measures can be aimed. The role of physical activity either as a preventive or causative factor for shoulder disorders has rarely been studied or even discussed. In our study, during the follow up of 1 year, physical exercise had more protective than impairing effects on the shoulders.

The Finnish Graduate school in Skeletal Diseases and the Finnish Work Environment Fund financially supported this study.

1 van der Windt DA, Thomas E, Pope DP, et al. Occupational risk factors for shoulder pain: a systematic review. Occup Environ Med 2000;57:433-42.

2 Hagberg M, Silverstein B, Wells R, et al. Work-related musculoskeletal disorders (WMSDs): a reference book for musculoskeletal disorders (WMSDs): a reference

prevention. London: Taylor and Francis, 1995 .
3 Bernard BP, ed. Musculoskeletal disorders and workplace factors: a critical review of epidemiologic evidence for work-related disorders of the neck, upper extremity, and low back. Cincinnati: National Institute of Occupational Safety and Health, 1997

4 Punnett L, Fine LJ, Keyserling WM, et al. Shoulder disorders and postural stress in automobile assembly work. Scand $\mathcal{F}$ Work Environ Health 2000;26:283-91.

5 Holmström EB, Lindell J, Moritz U. Low back and neck/shoulder pain in construction workers: occupational workload and psychosocial risk factors. Part 2: relationship to neck and shoulder pain. Spine 1992;17:672-7.

6 Ekberg K, Björkqvist B, Malm P, et al. Case-control study of risk factors for disease in the neck and shoulder area. Occup Environ Med 1994;51:262-6.

7 Pope DP, Croft PR, Pritchard CM, et al. Occupational factors related to shoulder pain and disability. Occup Environ
tope Med 1997;54:316-21.

8 Bouchard C, Shephard RJ, Stephens T, eds. Physical activity, fitness and health. International proceedings and consensus statement. Champaign: Human Kinetics, 1994:146-59. 
9 Lo YP, Hsu YC, Chan KM. Epidemiology of shoulder impingement in upper arm sports events. Br $\mathcal{F}$ Sports Med 1990;24:173-7.

10 Kujala UM, Taimela S, Antti-Poika I, et al. Acute injuries in soccer, ice hockey, volleyball, basketball, judo, and karate: analysis of national registry data. $B M 7$ 1995;311:1465-8.

11 Stenlund B. Shoulder tendinitis and osteoarthrosis of the acromioclavicular joint and their relation to sports. $\mathrm{Br} \mathcal{F}$ Sports Med 1993;27:125-30.

12 Miranda H, Viikari-Juntura E, Martikainen R, et al. Physical exercise and musculoskeletal pain among forest industry workers. Scand 7 Med Sci Sports (in press)

13 Viikari-Juntura E, Riihimäki H, Takala E-P, et al. Niskahartiaseudun ja yläraajan kipuja ennustavat tekijät metsäteollisuudessa. (Factors predicting pain in the neck, shoulders, and upper limbs in forestry work.) Työ ja Ihminen 1993; 7:233-253. (In Finnish with English summary.)

14 Kuorinka I, Jonsson B, Kilbom A, et al. Standardised Nordic questionnaires for the analysis of musculoskeletal sympquestionnaires for the analysis of
toms. Appl Ergon 1987;18:233-7.

15 Stenlund B, Goldie I, Hagberg M, et al. Radiographic osteoarthrosis in the acromioclavicular joint resulting from
manual work or exposure to vibration. Br f Ind Med 1992; manual wo

16 Oliveria SA, Felson DT, Cirillo PA, et al. Body weight, body mass index, and incident symptomatic osteoarthritis of the hand, hip, and knee. Epidemiology 1999;10:161-6.

17 Felson DT. Epidemiology of hip and knee osteoarthritis. Epidemiol Rev 1988;10:1-28.
18 Leino PI, Hänninen V. Psychosocial factors at work in relation to back and limb disorders. Scand $\mathcal{f}$ Work Environ tion to back and limb
Health $1995 ; 21: 134-42$.

19 Kaergaard A, Andersen JH. Musculoskeletal disorders of the neck and shoulders in female sewing machine operators: prevalence, incidence, and prognosis. Осcup Environ Med 2000;57:528-34.

20 van Mechelen W. Running injuries. A review of the epidemiological literature. Sports Med 1992;14:320-35.

21 Viikari-Juntura E, Riihimäki H, Tola S, et al. Neck trouble in machine operating, dynamic physical work and sedentary work: a prospective study on occupational and individual risk factors. $\mathcal{F}$ Clin Epidemiol 1994;47:1411-22.

22 Viikari-Juntura E, Rauas S, Martikainen R, et al. Validity of self-reported physical work load in epidemiologic studies on musculoskeletal disorders. Scand 7 Work Environ Health 1996;22:251-9.

23 Ainsworth BE, Montoye HJ, Leon AS. Methods of assessing physical activity during leisure and work. In: Bouchard C, . Shephard RJ, Stephens T, eds. Physical activity, fitness and health. International proceedings and consensus

24 Chasan-Taber S, Rimm EB, Stampfer MJ, et al. Reproducibility and validity of a self-administered physical activity questionnaire for male health professionals. Epidemiology 1996;7:81-6.

25 Kohl HW, Blair SN, Paffenbarger RS Jr, et al. A mail survey of physical activity habits as related to measured physical fitness. Am f Epidemiol 1988;127:1228-39.

\section{Narrative Based Medicine, An Interdisciplinary Conference}

\section{Research, Narrative, and Practice}

A two day conference-Monday 3rd and Tuesday 4th September 2001

\section{Homerton College, Cambridge, UK}

\section{BMF Publishing Group}

For full details contact: BMA/BMJ Conference Unit, Tavistock Square, London, WC1H 9JP Tel: +44 (0)20 7383 6819; fax: +44 (0)207383 6663; email: clyders@bma.org.uk.

www.quality.bmjpg.com 